\title{
NGHIÊN CỨU ĐĂC ĐIỂM LÂM SÀNG VÀ CẬN LÂM SÀNG CỦA BỆNH NHÂN NHỒI MÁU CO' TIM CẤP Có ST CHÊNH LÊN Có CAN THIỆP MẠCH VÀNH QUA DA THİ ĐẦU Ở BỆNH VIỆN HỮU NGHỊ ĐA KHOA NGHỆ AN
}

\author{
Ngô Đức Kỷ, Nguyễn Huy Lợi ${ }^{1}$, Trần Thị Anh Tho², Lê Thị Thúy ${ }^{2}$
}

TÓM TẮT

Mở đâu: Nhồi máu cơ tim cấp một trong những là nguyên nhân hàng đâu gây ra bệnh tật và tử vong trên toàn thế giới, là nguyên nhân thường gặp nhất đối với đau thắt ngực ở những bệnh nhân có bệnh lý tim mach nguy hiểm. NMCT cấp có ST chênh iên là bệnh khá phổ biến hiện nay, vì vậy chúng tôi nghiên cứu đề tài này. Mục tiêu: tìm hiểu đặc điểm lâm sàng và cận lâm sàng của bệnh nhân nhôi máu cơ tim cấp có STं chênh lên có can thiệp mạch vành qua da thì đâu. Phương pháp nghiên cứu: nghiên cứu mô tả cắt ngang. Tất cả có 106 bệnh nhân được chẩn đoán NMCT cấp có ST chênh lên được can thiệp mạch vành qua da thì đâu tại Bệnh viện Hữu Nghị đa khoa Nghệ An từ 1/2020-12/2020. Kết quả: Tuổi trung bình $71,67 \pm 13,13$ tuổi. Tuổi > 60 tuổi chiếm tỷ lệ 78,3\%. Nam giới có tỷ lệ $72,6 \%$ và nữ giới là $27,4 \%$. Các yếu tố nguy cơ của nhồi máu cơ tim như THA 58,5\%, rối loạn lipid máu 45,2\%. Triệu chứng đau ngực là $100 \%$, trong đó $78,3 \%$ là đau ngực điển hình. Điểm Killip của bệnh nhân chủ yếu ở nhóm Killip I và II với tỉ lệ lần lượt là $67 \%$ và $23,6 \%$. Tổn thương thường gặp nhất trên điện tâm đồ là NMCT vùng sau dưới với $49,1 \%$. Có 82 trường hợp tắc hoàn toàn và 24 trường hợp hẹp trên $70 \%$ trên hình ảnh chụp động mạch vành. Tỷ lệ hẹp $L A D$ và $R C A$ tương đương nhau là $47,17 \%$. Tổn thương 1 nhánh động mạch vành chiếm $64,2 \%$ nhưng cũng có đến $10,3 \%$ bệnh nhân có tổn thương 3 thân động mạch vành. Kết luân: Các bệnh nhân đều có yếu tố nguy cơ, đặc biệt là THA và rối loan lipid máu. Tất cả bênh nhân khởi phát với triêu chứng đau ngực, trong đó 78,3 \% là đau ngực điển hình. Vị trí tốn thương các nhánh độngng mạch vành đều gặp đặc biệt tổn thương 1 nhánh chiếm 64,2\% nhưng cũng có đến 10,3\% bệnh nhân có tổn thương 3 thân động mạch vành.

Tư khóa: nhồi máu cơ tim, động mạch vành, LAD.

\section{SUMMARY \\ CLINICAL AND SUBCLINICAL CHARACTERISTICS OF ACUTE MYOCARDIAL INFARCTION WITH ST ELEVATION AT NGHE AN GENERAL FREINDSHIP HOSPITAL \\ Backgruond: Acute myocardial infarction, the} first causes of morbidity and mortality worldwide, is the most frequent cause of angina in patients with

\footnotetext{
${ }^{1}$ Bệnh viện hữu nghị đa khoa Nghệ An

ªai họ Y Khoa Vinh

Chịu trách nhiệm chính: Ngô Đức Kỷ

Email: ngoduckyna@gmail.com

Ngày nhận bài: 12.4.2021

Ngày phản biện khoa học: 26.5.2021

Ngày duyệt bài: 14.6.2021
}

serious cardiovascular disease. ST-segment elevation acute MI is a fairly common disease today, so we study this topic. Objective: To study the clinical and laboratory characteristics of patients with ST-segment elevation acute myocardial infarction with early percutaneous coronary intervention. Methods: A cross-sectional descriptive study. All 106 patients diagnosed with acute MI with ST-segment elevation received percutaneous coronary intervention at the Huu Nghi Nghe An General Hospital from January 1, 2020 to December 12, 2020. Results: Mean age was $71.67 \pm 13.13$ years old. Age $>60$ years old accounts for $78.3 \%$. Male rate is $72.6 \%$ and female rate is $27.4 \%$. Risk factors for myocardial infarction such as hypertension $58.5 \%$, dyslipidemia $45.2 \%$. Symptoms of chest pain are $100 \%$, of which $78.3 \%$ are typical chest pain. The patient's Killip score was mainly in the Killip I and II groups with the rate of $67 \%$ and $23.6 \%$, respectively. The most common lesion on electrocardiogram was posterior inferior MI with $49.1 \%$. There were 82 cases of complete occlusion and 24 cases of stenosis over $70 \%$ on coronary angiography. The rate of LAD stenosis and RCA was similar at $47.17 \%$. Injury to one coronary artery accounted for $64.2 \%$ but also $10.3 \%$ of patients had damage to 3 coronary arteries. Conclusion: All patients had risk factors, especially hypertension and dyslipidemia. All patients had onset of chest pain, of which $78.3 \%$ were typical chest pain. The location of damage to the coronary artery branches is common, especially damage to one branch, accounting for $64.2 \%$, but also up to $10.3 \%$ of patients have damage to 3 coronary arteries. LAD.

Keywords: myocardial infarction, coronary artery,

\section{I. ĐĂT VẤN ĐỀ}

Nhồi máu cơ tim (NMCT) cấp là một trong những nguyên nhân hàng đâu gây ra bệnh tật và tử vong trên toàn thế giới, mặc dù tiên lượng đã được cải thiện đáng kể trong thập kỷ qua. Ớ Mỹ, tỷ lệ tử vong do nhôi máu cơ tim khoảng $30 \%$, trong đó một nửa số bệnh nhân bị chết trong giờ đầu tiên [1]. Ở Pháp, tỷ lệ tử vong do nhồi máu cơ tim cũng vào khoảng $30 \%$ các tử vong nói chung [2]. Tại Việt Nam, các nghiên cứu cũng cho thấy số ca bị NMCT cấp và tử vong do NMCT cũng ngày một tăng $[3,4,5]$. NMCT cấp vẫn là một vấn đề sức khỏe cộng đồng được quan tâm ở các nước phát triển và ngày càng trở nên thời sự hơn ở các nước đang phát triển trong đó có Việt Nam. NMCT thường gặp ở người có tiền sử bị xơ vữa động mạch, hút thuốc 
lá, mắc bệnh tăng huyết áp, rối loạn lipid máu, đái tháo đường, thừa cân béo phì,... Nguy cơ mắc NMCT tăng theo tuổi và cao hơn ở nam giới, cho dù nguy cơ ở nữ gia tăng đáng kể ở độ tuối 5 đến 10 năm sau mãn kinh. Thay đổi lối sống, điều trị thuốc hoặc kết hợp cả hai biện pháp có thể giúp điều chỉnh được các yếu tố nguy cơ ngoại trừ yếu tố di truyền, tuổi và giới [5]. Ở Việt Nam đã có nhiều nghiên cứu đề cập đến vấn đề này, tại Nghệ An cũng có nhiều bệnh nhân bị NMCT cấp tuy nhiên chưa có nghiên cứu nào tại Nghệ An đề cập đến. Vì vậy chúng tôi tiến hành nghiên cứu này với mục đích tìm hiểu các đặc điểm lâm sàng và cận lâm sàng ở bệnh nhân nhồi máu cơ tim có ST chênh lên.

\section{II. ĐỐI TƯỢNG VÀ PHƯƠNG PHÁP NGHIÊN CỨU}

Đối tượng nghiên cứu. Bệnh nhân được chẩn đoán NMCT cấp có ST chênh lên được can thiệp mạch vành qua da thì đầu tại Bệnh viện Hữu Nghị đa khoa Nghệ An từ 1/2020-12/2020.

Tiêu chuẩn loại trừ: Bệnh nhân đã sử dụng thuốc tiêu sợi huyết trước đó. Bệnh nhân không đồng ý tham gia nghiên cứu.

Phương pháp nghiên cứu: mô tả cắt ngang.

Cỡ mẫu: chọn mẫu thuận tiện theo trình tự thời gian đối với tất cả bệnh nhân đủ

Phương pháp tiến hành. Chọn những bệnh nhân thỏa mãn tiêu chuẩn chọn bệnh sau đó thăm khám lâm sàng và ghi nhận các kết quả cận lâm sàng qua hồ sơ bệnh án theo phiếu thu thập số liêu.

Các tiêu chuẩn đánh giá sử dụng trong nghiên cứu

- Chẩn đoán NMCT cấp có ST chênh lên theo tiêu chuẩn WHO 1971 hoặc theo Định nghĩa toàn câu lần thứ IV về NMCT cấp năm 2018.

- Phân độ suy tim cấp theo Killip.

Xử lý và phân tích số liệu bằng phần mềm thống kê SPSS 20.0

\section{KẾT QUẢ NGHIÊN CỨU}

1.Đặc điểm nhóm nghiên cứu

Bảng 1.Đặc điểm nhóm nghiên cứu

\begin{tabular}{|c|c|c|c|}
\hline \multicolumn{2}{|c|}{ Đặc điểm } & $\begin{array}{c}\text { Tần suất } \\
(\mathbf{n})\end{array}$ & $\begin{array}{c}\text { Tỷ lệ } \\
(\%)\end{array}$ \\
\hline \multirow{4}{*}{ Tuổi } & $\begin{array}{c}\text { Trung } \\
\text { bình }\end{array}$ & $\begin{array}{c}71,67 \pm \\
13,13\end{array}$ & \\
\cline { 2 - 4 } & $<50$ & 6 & 5,7 \\
\cline { 2 - 4 } & $50-60$ & 17 & 16,0 \\
\cline { 2 - 4 } & $>60$ & 83 & 78,3 \\
\hline \multirow{2}{*}{ Giới } & Nam & 77 & 72,6 \\
\cline { 2 - 4 } & Nữ & 29 & 27,4 \\
\hline Hút thuốc lá & & 21 & 19,8 \\
\hline Rối loạn lipid máu & & 48 & 45,2 \\
\hline
\end{tabular}

\begin{tabular}{|c|l|l|l|}
\hline Đái tháo đường & & 14 & 13,2 \\
\hline THA & & 62 & 58,5 \\
\hline Thừa cân/béo phì & & 27 & 25,8 \\
\hline
\end{tabular}

Nhận xét tất cả có 106 bênh nhân đủ tiêu chuẩn nghiên cứu. Tuổi trung bình $71,67 \pm 13,13$ tuổi. Đa số gặp lứa tuổi $>60$ tuổi chiếm tỳ lệ $78,3 \%$. Gần như các bệnh nhân đều có yếu tổ nguy cơ, đặc biệt là THA và rối loạn lipid máu.

\section{2. Đặc điểm lâm sàng}

Bảng 2. Đặc điểm lâm sàng bệnh nhân NMCT cấp

\begin{tabular}{|c|c|c|c|}
\hline \multicolumn{2}{|r|}{ Đặc điểm } & \multirow{2}{*}{$\begin{array}{c}\text { Tân số } \\
\text { (n) }\end{array}$} & \multirow{2}{*}{$\begin{array}{c}\text { Tỷ lệ } \\
\text { (\%) }\end{array}$} \\
\hline \multirow{3}{*}{$\begin{array}{l}\text { Tính chất } \\
\text { đau ngực }\end{array}$} & Đau ngực điến hình & & \\
\hline & $\begin{array}{l}\text { Dau ngực không } \\
\text { điển hình }\end{array}$ & 23 & 21,7 \\
\hline & Không đau ngực & 0 & 0 \\
\hline \multirow{3}{*}{$\begin{array}{c}\text { Mức độ } \\
\text { đau ngực }\end{array}$} & Đau nhe (VAS $\leq 3$ ) & 1 & 0,9 \\
\hline & $\begin{array}{l}\text { Dau trung bình } \\
\text { (VAS 4-6) }\end{array}$ & 43 & 40,6 \\
\hline & Đau nhiều (VAS $\geq 7$ ) & 62 & 58,5 \\
\hline \multirow{4}{*}{ Khó thở } & NYHA I & 6 & 15 \\
\hline & NYHA II & 63 & 59,4 \\
\hline & NYHA III & 29 & 27,4 \\
\hline & NYHA IV & 2 & 1,9 \\
\hline \multirow{4}{*}{$\begin{array}{l}\text { Triêu } \\
\text { chứng } \\
\text { khác }\end{array}$} & Mệt mỏi & 60 & 56,6 \\
\hline & Vã mồ hôi & 53 & 50 \\
\hline & Rối loạn ý thức & 4 & 3,8 \\
\hline & Rối loạn tiêu hóa & 4 & 3,8 \\
\hline \multirow{4}{*}{ Điểm Killip- } & I & 75 & 67 \\
\hline & II & 21 & 23,6 \\
\hline & III & 0 & 0 \\
\hline & & & \\
\hline
\end{tabular}

Nhân xét: Tất cả bênh nhân khởi phát với triệu chứng đau ngực, trong đó $78,3 \%$ là đau ngực điển hình. Có 94,3\% bệnh nhân khó thở kèm theo và ở mức độ NYHA II-III là chủ yếu. Điểm Killip của bệnh nhân chủ yếu ở nhóm Killip I và II với tỉ lệ lần lượt là $67 \%$ và $23,6 \%$.

\section{3.Đặc điểm cận lâm sàng} tâm đồ

Bảng 3. Đặc điểm NMCT cấp trên điện

\begin{tabular}{|c|c|c|}
\hline Vị trí NMCT & $\begin{array}{c}\text { Tân suất } \\
\text { (n) }\end{array}$ & $\begin{array}{c}\text { Tỷ lệ } \\
(\mathbf{\%})\end{array}$ \\
\hline Thành trước & 24 & 22,6 \\
\hline Thành trước rộng & 27 & 25,5 \\
\hline Thành sau dưới & 52 & 49,1 \\
\hline Thành bên & 2 & 1,9 \\
\hline Thất phải & 1 & 0,9 \\
\hline
\end{tabular}

Nhận xét: Tốn thương thường gặp nhất trên điện tầm đồ là NMCT vùng sau dưới với $49,1 \%$, vùng trước vách và trước rộng có tỉ lệ tương đương nhau là $22,6 \%$ và $25,5 \%$, thấp nhất là vùng thất phải. 
Bảng 4. Đặc điểm tổn thương động mạch vành bằng DSA

\begin{tabular}{|c|c|c|c|c|c|c|}
\hline \multirow{2}{*}{ Đăc điểm } & \multicolumn{2}{|c|}{ Hẹp > $70 \%$} & \multicolumn{2}{|c|}{ Tăc hoàn toàn } & \multicolumn{2}{|c|}{ Chung } \\
\hline & $n=24$ & Tỷ lệ (\%) & $n=82$ & Tỷ lệ (\%) & $n=106$ & Tỷ lệ (\%) \\
\hline Thân chung & 1 & 4,16 & 1 & 1,21 & 2 & 1,9 \\
\hline LAD & 13 & 54,16 & 37 & 45,12 & 50 & 47,17 \\
\hline LCX & 1 & 4,16 & 3 & 3,66 & 4 & 3,76 \\
\hline RCA & 9 & 37,52 & 41 & 50,01 & 50 & 47,17 \\
\hline
\end{tabular}

Nhận xét: có 82 trường hợp tắc hoàn toàn và 24 trường hợp hẹp trên $70 \%$ trên hình ảnh chụp động mạch vành. Tỷ lệ hẹp LAD và RCA tương đương nhau là 47,17\%.

Tỷ lệ các nhánh ĐMV tổn thương

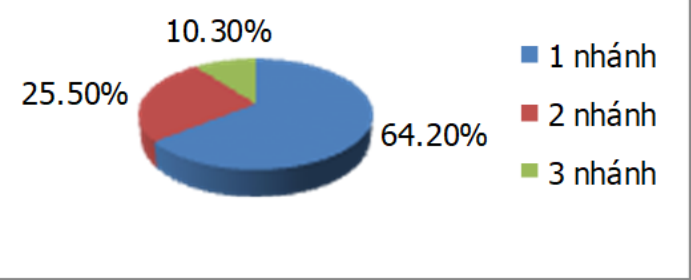

Biểu đồ 1. Tỷ lệ các nhánh ĐMV tổn thương

Nhân xét: Đa số bênh nhân chỉ tổn thương 1 nhánh chiếm $64,2 \%$ nhưng cũng có đến 10,3\% bệnh nhân có tổn thương 3 thân động mach vành.

\section{BÀN LUẬN}

Đặc điểm nhóm nghiên cứu. Trong nghiên cứu của chúng tôi có 106 bệnh nhân đáp ứng đủ tiêu chuẩn nghiên cứu, trong đó tỉ lệ bệnh nhân nam chiếm ưu thế với $72,6 \%$, gấp 2,66 lần số bệnh nhân nữ, tî lệ này tương đương với các nghiên cứu trong nướ[ $[3,4,5]$. Theo nghiên cứu, không có trường hợp nữ giới nào dưới 50 tuổi bị NMCT. Tuổi trung bình của nữ giới cũng cao hơn của nam giới $(74,79 \pm 12,70$ so với $70,49 \pm 13,12)$. Điều này phù hợp với nguy cơ xuất hiện biến cố tim mạch muộn ở nữ giới, cụ thể là sau nam giới khoảng 10 năm [6]. Tuổi chúng tôi ghi nhận được tuổi thấp nhất là 44, cao nhất là 99 tuổi và tuổi trung bình là $71,67 \pm 13,13$ tuổi. Tuổi trung bình trong nghiên cứu của chúng tôi nằm ở ngưỡng tuổi có nguy cơ cao bệnh mạch vành là $\geq 65$ tuổi. Các nghiên cứu về yếu tố nguy cơ bệnh mạch vành đã chứng minh tuổi cao trên 65 làm gia tăng nguy cơ mắc bệnh cũng như gia tăng biến cố của bệnh mạch vành [6].

Tăng huyết áp và rối loạn mõ máu là những yếu tố rất quan trọng trong cơ chế bệnh sinh của bệnh mạch vành, đặc biệt là NMCT. Trong nhóm các yếu tố nguy cơ, chúng tôi ghi nhận nhóm có tỉ lệ cao nhất là tăng huyết áp chiểm $58,5 \%$ và rối loạn lipid máu là $45,2 \%$. Điều này tương tự như các nghiên cứu trong nước $[3,4,5,6]$ tuy nhiên tỷ lệ có khác nhau giữa các nghiên cứu có thể do sự khác nhau về đối tượng, thiết kế nghiên cứu, hay vùng miền,... Ngoài ra các yếu tố khác như hút thuốc lá, bệnh nền đái tháo đường, thừa cân/béo phì cũng tương tự như trên và yếu tố nguy cơ của NMCT cấp.

Đặc điểm triệu chứng lâm sàng. Tất cả bênh nhân vào viện đều khởi phát với triệu chứng đau ngực, trong đó có $78,3 \%$ là đau ngực điển hình.Theo nghiên cứu của Nguyễn Văn Tân tại Bệnh viện Thống Nhất, đau ngực 87,7\% [3] hay tác giả Nguyễn Thị Thanh Trung [5] đau ngực điển hình $82,1 \%$. Đây là lí do khiến bệnh nhẩn nhập viện và định hướng tới NMCT. Bệnh nhân đau ngực điển hình kèm theo khó thở và vã mồ hôi, đây là những triệu chứng điển hình của NMCT cấp. Bên cạnh triệu chứng chính là đau ngực thì có đến $94,3 \%$ bệnh nhân có kèm theo khó thở với nhiều mức độ khác nhau, trong đó chủ yếu khó thở ở mức độ NYHA II-III, với 92\%.

Tỉ lệ bệnh nhân bị suy tim theo phân độ Killip, gặp chủ yếu là Killip I và II lân lượt là $67 \%$ và $23,6 \%$ đặc biệt Killip IV là $9,43 \%$. Tỉ lệ này tương tự với nghiên cứu với nghiên cứu của Huỳnh Kim Phượng [4] Killip I, II với tỉ lệ lần lượt là $50,8 \%, 24,2 \%$; Killip IV là $8,6 \%$ và Nguyễn Thị Thanh Trung thì tỉ lệ bệnh nhân có Killip I là $32,15 \%$, II là $25,01 \%$ và Killip IV là $10,7 \%$ [5]. Những bệnh nhân Killip IV đước hồi sức và nhanh chóng được can thiệp mạch vành thì đầu và thường có vùng nhồi máu rộng, lớn, như trước vách, trước rộng và hường tổn thương nhánh chính của ĐMV hoặc tổn thương nhiều nhánh ĐMV.

Đặc điểm cận lâm sàng. Tổn thương thường gặp nhất trên điện tâm đồ là NMCT vùng sau dưới với $49,1 \%$, vùng trước vách và trước rộng có tỉ lệ tương đương nhau là $22,6 \%$ và $25,5 \%$, thấp nhất là vùng thất phải. Tương tự với kết quả này ở nghiên cứu của Trân Hòa là $52,2 \%$ và $47,8 \%$ [7]. Trong nghiên cứu của chúng tôi có $4,7 \%$ bệnh nhân có block nhĩ nhất cấp 3 do biến chứng của NMCT, các trường hợp này đều được đặt máy tạo nhịp trước can thiệp. Tỷ lệ hẹp động mạch vành phải và động mạch vành trái tương đương nhau là $47,17 \%$ trong đó 
có 82 trường hợp tắc hoàn toàn và 24 trường hợp hẹp trên $70 \%$ trên hình ảnh chụp động mạch vành. Hầu hết bênh nhân chỉ tổn thương 1 nhánh chiếm $64,2 \%$ nhưng cũng có đến $10,4 \%$ bênh nhân có tổn thương 3 thân động mạch vành. Những bệnh nhân tổn thương 3 thân động mạch vành thường có tiền sử đau thắt ngực trước đó và có nhiều yếu tố nguy cơ kèm theo. Theo tác giả Huỳnh Kim Phượng thì $71,1 \%$ có hẹp nhánh liên thất trước động mạch vành trái, $53,1 \%$ có hẹp nhánh mũ và $56,2 \%$ có hẹp động mạch vành phải khi nghiên cứu ở bệnh nhân đái tháo đường type 2 [4]. Kết quả của chúng tôi phù hợp với nghiên cứu của Nguyễn Văn Tần cũng cho thấy tỷ lệ động mạch vành phải là 43,1\%[3] và Trần Hòa là đọng mach liên thất trước $47 \%$, động mạch vành phải $43 \%$ và động mạch mũ $10 \%$ [7].

\section{KẾT LUÂN}

Đa số gặp lứa tuổi > 60 tuổi chiếm tỷ lệ $78,3 \%$. Gần như các bệnh nhân đều có yếu tổ nguy cơ, đặc biệt là THA và rối loạn lipid máu. Tất cả bệnh nhân khởi phát với triệu chứng đau ngực, trong đó 78,3 \% là đau ngực điển hình. Vị trí tổn thương các nhánh động mạch vành đều gặp đặc biệt tổn thương 1 nhánh chiếm 64,2\% nhưng cũng có đến $10,3 \%$ bệnh nhân có tổn thương 3 thân động mạch vành.

\section{TÀI LIÊU THAM KHẢO}

1. Jayaraj J.C., Davatyan K., Subramanian S.S., et al (2018). Epidemiology of Myocardial Infarction. Myocard Infarct.

2. Sanchis-Gomar F., Perez-Quilis $C_{\text {., Leischik }}$ R., et al (2016). Epidemiology of coronary heart disease and acute coronary syndrome. Ann Transl Med 2016;4(13):256.

3. Nguyễn Văn Tân, Châu Văn Vinh (2019). Nghiên cứu đăc điểm tổn thương đông mach vành ở bệnh nhân cao tuổi nhồi máu cơ tin cấp thất phải. Tap chí y hoc TP. Hồ Chí Minh, 23(2):176 - 181.

4. Huỳnh Kím Phượng, Trương Thành Viễn (2016). Đặc điểm lẩm sàng và cận lâm sàng bệnh nhân tữ 45 tuổi trở lên bi nhồi máu cơ tim cấp kèm đái tháo đường type 2 (2016). Tạp chí y học TP. Hồ Chí Minh, 20(2):220-233.

5. Nguyê̂n Thị Thanh Trung (2014). Nghiên cứu đặc điểm lâm sàng và cận lâm sàng, kết quả điêu trị nhồi máu cơ tim cấp có ST chênh lên tại bệnh việ đa khoa Thái Bình. Y học thực hành (905). Số 2/2014, tr 16-19.

6. Lê Cao Phương Duy (2019). Hiệu quả sớm của thủ thuật hút huyết khối trong can thiêp mach vành qua da thì đâu ở bênh nhân nhồi máu cơ tim cấp có ST chênh lên. Tạp chí y học TP. Hồ Chí Minh, 23(6):83-90.

7. Trân Hòa, Vũ Văn Hoàng, Nguyễn Hữu Khoa Nguyên, Trương Quang Bình (2012). Kết quả can thiệp động mạch vành tiên phát (thì đâu) trong điều trị nhồi máu cơ tim cấp có ST chênh lên tai Bênh viên Y Dước TP Hồ Chí Minh.Tap chí Y Học Thành Phố Hồ Chí Minh, 16(1):94-100.

\section{GIST ĐAI TRÀNG Ở TRẺ EM: BÁO CÁO CA BỆNH VÀ TỔNG QUAN Y VĂN}

\section{TÓM TẮT}

Mục đích: Báo cáo ca bệnh hiếm gặp u mô đệm ông tiểu hoá (GIST) của đại tràng ở tré em. Phướng pháp: Báo cáo ca bệnh và tổng quan y văn. Kết quả: Bệnh nhân (BN) nữ 13 tuổi vào viện vì đau bụng cơn, nổn, đai tiên phân máu. Siêu âm ổ bung phát hiên khối lồng ruột đại- đại tràng, vị trí hạ sườn trái, kích thước 54 x 43 x 51mm. Cắt lớp vi tính thây khối lồng với tổ chức nghi u đại tràng xuống. Nội soi đại tràng thấy u đại tràng xuống kích thước 40 x $30 \mathrm{~mm}$, có hoai tử trung tâm. BN được phẫu thuật nội soi cấp cứu tháo lồng ruột. Sau phẩu thuật 1 ngày BiN bi lồng ruột

*Bênh viên Đa khoa Saint Paul

Chịu trách nhiệm chính: Nguyễn Thị Hồng Vân

Email: hongvanyd@gmail.com

Ngày nhân bài: 14.4.2021

Ngày phản biên khoa họ: 26.5.2021

Ngày duyệt bài: 15.6.2021
Nguyễn Thị Hồng Vân*, Lương Anh Quân, Trẩn Văn Quyết*; Trần Ngọc Sơn*

tái phát với các triệu chứng tắc ruột, được phẫu thuât cấp cứu cắt đoạn đại tràng trái với mép cắt cách khối u $3-5 \mathrm{~cm}$. Kết quả giải phẫu bênh là u GIST và diên cắt vi thể không có tế bào u. Sau mổ bệnh nhân hồi phục tốt, ra viện sau mổ 7 ngày. Theo dổi 3 năm không có biến chứng và không thây u tái phát hay di că̆n. Kết luân: U GIST đại tràng hiếm găp ở trẻ em. Phẫu thuất triệt căn cắt đoạn đại tràng với mép cắt trên và dưới âm tính là phướng pháp điêu trị hiệu quả trong bệnh lý này trong giai đoạn u tại chỗ.

Tư khoá: U GIST trẻ em, đại tràng.

\section{SUMMARY}

\section{COLONIC GIST IN CHILDREN: A CASE}

REPORT AND LITERATURE REVIEW

Aim: Report a rare case of colonic GIST in a treatment child. Method: A case report and literature review. Result: A 13 years old girl was admitted to our center for abdominal pain, bilious vomiting and hematochezia. Abdomainal ultrasound showed a 